\title{
miR-194 Suppresses Proliferation and Migration and Promotes Apoptosis of Osteosarcoma Cells by Targeting CDH2
}

\author{
Jinglei Miao ${ }^{\mathrm{a}}$ Weiguo Wang ${ }^{\mathrm{a}}$ Song Wu $\mathrm{Wiaofang}^{\mathrm{a}}$ Zang ${ }^{\mathrm{a}}$ Yuezhan $\mathrm{Li}^{\mathrm{a}}$ \\ Jianlong Wanga Ruisen Zhan ${ }^{a}$ Minwei Gao ${ }^{d}$ Minghua Huc Jinsong Lia \\ Shijie Chen ${ }^{a, b}$
}

aDepartment of Orthopaedics, The Third Xiangya Hospital of Central South University, Changsha, bShanghai Key Laboratory of Regulatory Biology, Institute of Biomedical Sciences and School of Life Sciences, East China Normal University, Shanghai, 'Department of Anatomy, Histology and Embryology, Changsha Medical University, Changsha, 'Department of Orthopaedics, Hunan Aerospace Hospital, Changsha, China

\section{Key Words}

Mir-194 •Proliferation • Migration $\cdot$ Apoptosis $\cdot \mathrm{CDH} 2 \cdot$ Osteosarcoma

\begin{abstract}
Background/Aims: Studies have shown that miR-194 functions as a tumour suppressor and is associated with tumour growth and metastasis. This study intends to uncover the mechanism of tumour suppression by miR-194. The expression of miR-194 in osteosarcoma cell lines and tissues were monitored by real-time PCR. Methods: The proliferation ability was examined by MTT assay. Migration and apoptosis of cells were monitored by migration assay and flow cytometry, respectively. The regulation of miR-194 on $\mathrm{CDH} 2$ was determined by luciferase assays and western blot assays. Results: The results showed that miR-194 was significantly reduced in osteosarcoma compared with that in normal bone tissue. Overexpression of miR194 significantly attenuated the proliferation and migration and induced the apoptosis of osteosarcoma cells. Furthermore, we demonstrated that miR-194 has inhibited the malignant behaviour of osteosarcoma by downregulating $\mathrm{CDH} 2$ expression. Conclusions: These findings suggested that miR-194 may act as a tumour suppressor in osteosarcoma. miR-194/CDH2 may be a novel therapeutic target in the treatment of osteosarcoma.

(C) 2018 The Author(s)

Published by S. Karger AG, Basel
\end{abstract}

\section{Introduction}

Osteosarcoma is the most common malignant bone tumour, accounting for $17 \%$ of primary bone tumours and $42 \%$ of primary malignant bone tumours. It is characterized

J. Miao, W. Wang and S. Wu contributed equally to this work.

Shijie Chen, Jinsong Li and Minghua $\mathrm{Hu}$

\section{KARGER}

Department of Orthopaedics, The Third Xiangya Hospital of Central South University, Department of Anatomy, Histology and Embryology, Changsha Medical University (China) E-Mail shijiechencs@163.com, jinsongli1982@sina.com, minghuahucsmu@163.com 


\section{Cellular Physiology Cell Physiol Biochem 2018;45:1966-1974

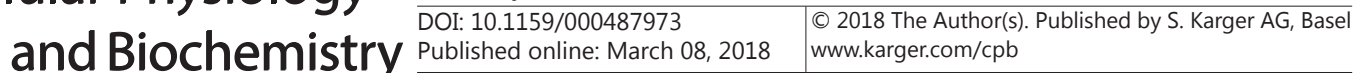

by high incidence in adolescence, early lung targeted metastasis and poor prognosis. The most effective regimens currently include neoadjuvant and adjuvant chemotherapy coupled with local control that usually consists of limb-sparing surgery [1]. With the development of therapeutic methods, the survival rate of patients suffering from osteosarcoma has improved. However, the cure rate is still very poor due to pulmonary metastases [2]. Thus, a fundamental quest in the mechanism of osteosarcoma development and metastasis is imperative. Looking for novel molecular markers in osteosarcoma for early diagnosis, prognostic evaluation and bio-therapeutics may have a significant effect in improving the current situation of diagnosis and treatment.

MicroRNAs (miRNAs) are a class of short noncoding RNAs thatnegatively regulate gene expression by inducing mRNA degradation or translation repression by targeting the 3' untranslated region (3'UTR) of mRNAs [3]. Aberrant expression of miRNAs has been observed in human cancers and has been shown to be involved in a variety of critical cellular processes, including cell differentiation, proliferation and metabolism [4]. The alterations in miRNA expression may play a crucial role in the initiation and progression of cancers [5], functioning as a novel class of oncogenes or tumour suppressors [6, 7]. Previous studies showed that miR-194 has functioned as a tumour suppressor in various types of cancers [810]. However, the role of miR-194 in osteosarcoma cancer progression is still unclear.

In the present study, we first investigated the expression level of miR-194 in osteosarcoma cancer cell lines and clinical tissues. The mechanism of miR-194 in cell migration and apoptosis in osteosarcoma cancer cell lines was then examined. In addition, the potential downstream targets of miR-194 were also investigated.

\section{Materials and Methods}

\section{Cell culture}

Human osteosarcoma cell lines (U2OS and MG-63) and normal human osteoplastic cell line (hFOB) were purchased from the Type Culture Collection of the Chinese Academy of Sciences (Shanghai, China) and maintained in Dulbecco modified Eagle medium (DMEM, Hyclone, USA) supplemented with 10\% fetal bovine serum (FBS; Hyclone, USA), $100 \mathrm{U} / \mathrm{mL}$ penicillin and $100 \mathrm{ng} / \mathrm{mL}$ streptomycin in condition of at $37^{\circ} \mathrm{C}$ temperature with $5 \% \mathrm{CO}_{2}$ and $95 \%$ air.

Clinical tissue samples

Osteosarcoma cancer tissue samples were acquired from The Third Xiangya Hospital of Central South University. Osteosarcoma cancer tissues and normal adjacent normal tissues were collected from 20 patients undergoing resection of tumours at The Third Xiangya Hospital of Central South University. All specimens, clinical information and procedures were approved by the Clinical Research Ethics Committee of The Third Xiangya Hospital of Central South University. Patients were included in the study after written informed consent approved by the ethics committee. All tissues were snap-frozen in liquid nitrogen for further quantitative real-time polymerase chain reaction (qRT-PCR) analysis.

\section{Cell transfection}

Primers and miR-194 mimic, miR-194 inhibitor and siRNA against CDH2 and their respective negative controls (NCs) were synthesized by GenePharma (Shanghai, China). The pcDNA3.1 plasmid and pcDNA3.1CDH2 plasmid were purchased from Genscript (Shanghai, China). All transfection was conducted with Lipofectamine 2000 (Invitrogen, USA), according to the manufacturer's instructions.

Reverse transcription and quantitative real-time PCR

Total RNA and miRNA were extracted from cells with TRIzol@ reagent (Invitrogen, CA, USA) or from tissue samples with RecoverAll ${ }^{\mathrm{TM}}$ Total Nucleic Acid Isolation kit (Ambion, Foster City, CA, USA), according to the manufacturer's instructions. RNA was reverse transcribed into cDNA using PrimeScript RT reagent kit (TaKaRa, Dalian, China). microRNA extraction was performed using the microRNA Extraction kit (Tiangen, Beijing,China).qRT-PCR was performed with SYBR Premix Ex Taq (TaKaRa, Dalian, China). The primers formiR- 


\section{Cellular Physiology Cell Physiol Biochem 2018;45:1966-1974

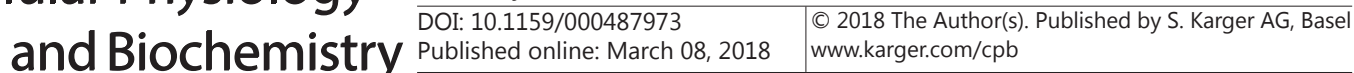 \\ Miao et al.: MiR-194 Down-Regulation of Osteosarcoma by Targeting CDH2}

194 are as follows: forward, 5'-ATGGACCTGGGGCCAGCGAAG-3' and reverse, 5'-TCTGGCCTGGGAGCGTCG-3'; the primers for CDH2 mRNA are: forward, 5'-GTCAGCAGAAGTTGAAGAAATAGTG-3' and reverse, 5'-GCAAGTTGATTGGAGGGATG-3'.

\section{MTT assay}

Cultured cells were grown in 6-, 24- and 96-well plates. Apoptosis was measured by flow cytometry. Cell viability was examined using the 3-(4, 5-dimethylthiazol-2-yl)-2, 5-di-phenyltetrazolium bromide (MTT) assay. MTT was performed at 24, 48, 72, 96, 120 and $144 \mathrm{~h}$ incubation. The absorbance at $492 \mathrm{~nm}$ was measured after incubation with $20 \mu \mathrm{L}$ of MTT for $4 \mathrm{~h}$. The curve of cell proliferation was then drawn, and the proliferation efficiency was examined. The experiments were repeated three times independently.

\section{Transwell cell migration assay}

The migration potential of cells was measured in a 6.5-mm Transwell with an 8.0-mm pore polycarbonate membrane insert (Corning, NY). The lower chambers were filled with $600 \mu \mathrm{L}$ of DMEM medium containing $10 \%$ FBS as a chemoattractant. The suspension of 5, 000 cells in $100 \mu \mathrm{L}$ of migration medium was added into each top chamber. After incubation for $16 \mathrm{~h}$, the non-migrating cells that remained on the upper surface were removed with a cotton swab. The migrated cells in the lower surface were fixed with $4 \%$ paraformaldehyde for $30 \mathrm{~min}$, permeabilized with $0.2 \%$ Triton X-100 at room temperature for $15 \mathrm{~min}$ and stained with $0.1 \%$ crystal violet for $5 \mathrm{~min}$. The experiments were repeated three times independently.

\section{Luciferase assay}

For target gene assays, the 3'UTR of human CDH2 was amplified using PCR and cloned into a pmirGLO vector. U2-OS cells of 70\% confluence in 24-well plates were transfected using Lipofectamine 2000. The constructed wild type or mutant pmirGLO vector (100 ng), $5 \mathrm{ng}$ of pRL-SV40 Renilla luciferase construct (for normalization), and $100 \mathrm{ng}$ of miR-194 mimic, miR-194 inhibitor or their respective NCs were cotransfected per well. Cell extracts were prepared at $48 \mathrm{~h}$ after transfection, and the luciferase activity was measured after $48 \mathrm{~h}$ using the Dual luciferase reporter assay system (Promega).

Western blot analysis

Proteins were extracted from whole cell lysates and separated by sodium dodecyl sulfate-polyacrylamide gel electrophoresis, then transferred to a polyvinylidene fluoride (PVDF) membrane. The rabbit anti-CDH2 (1:1500; Abcam, Cambridge, USA) and mouse anti- $\beta$-actin (1:6000; Cell Signalling Technology) were used. The membranes were then incubated with secondary antibodies (1:5000; Abcam, Cambridge, USA). Then, the membrane was treated with chemiluminescence reagents (Santa Cruz) as per the manufacturer's instructions and analysed by ImageJ software.

\section{Statistical analysis}

All statistical analysis was carried out using the SPSS 18.0 software (SPSS, Inc., Chicago, IL, USA). All values were expressed as the mean \pm standard deviation from at least three repeated individual experiments for each group. The differences among groups were analysed by one-way ANOVA followed by Bonferroni's multiple comparison tests or t-test, as appropriate. All data were expressed as the mean \pm SD. Differences were considered significant when $\mathrm{P}<0.05$.

\section{Results}

miR-194 was downregulated in osteosarcoma cancer cell lines

We first examined the differential expression of miR-194 in a normal human osteoplastic cell line (hFOB) and human osteosarcoma cell lines (U20S and MG-63). Compared with the normal osteoplastic cell line, miR-194 was significantly downregulated in the osteosarcoma cell lines (Fig. 1, $\mathrm{P}<0.05$ ). These results indicated that miR-194 was downregulated in osteosarcoma cell lines. 
Fig. 1. miR-194 has decreased expression in human osteosarcoma cell lines. The expression levels of miR194 in hFOB, U2OS and MG-63 cell lines were measured by qRT-PCR. Data are represented by the mean \pm SD from three independent experiments $(* \mathrm{P}<0.05)$.

\section{miR-194 negatively regulates cell proliferation} and migration

miR-194 mimic, miR-194 inhibitor, and a control lentiviral empty vector were stably transfected into human osteosarcoma cancer cell lines (MG-63 and U20S). The MTT results showed that the MG-63 cells with overexpression of miR-194 exhibited a significant decline in the proliferation capacity compared with the other three groups (Fig. 2A, p<0.05). In contrast, cells in the knocked down miRNA-194 group showed significantly enhanced proliferation (Fig. 2A, $\mathrm{P}<0.05)$. No significant difference was found between the blank groups and control groups. The results of U2OS cells were similar to the stably transfected MG-63 cells (Fig. 2B, $\mathrm{P}<0.05$ ). The results in the transwell migration assay showed a significantly lower number of overexpressed miR-194 in MG-63 cells, compared with the blank control and knocked down miRNA-194 in MG63 cells (Fig. 2C, p<0.05). No significant difference was observed between the blank and control MG-63 cells. Similar results were obtained in U2OS cell lines (Fig. 2D, p<0.05), which strongly indicated that miR194 had an important role in reducing osteosarcoma migration in vitro.

Overexpression of miR194 promoted OS cell apoptosis

The Annexin-V-FITC/ PI staining method was used to detect apoptosis of MG-63 and U2OS cells. The results demonstrated that the cell apoptosis rate was increased following transfection with the miR194 mimics, not only in the MG-63 cells but also in the U20S cells, compared

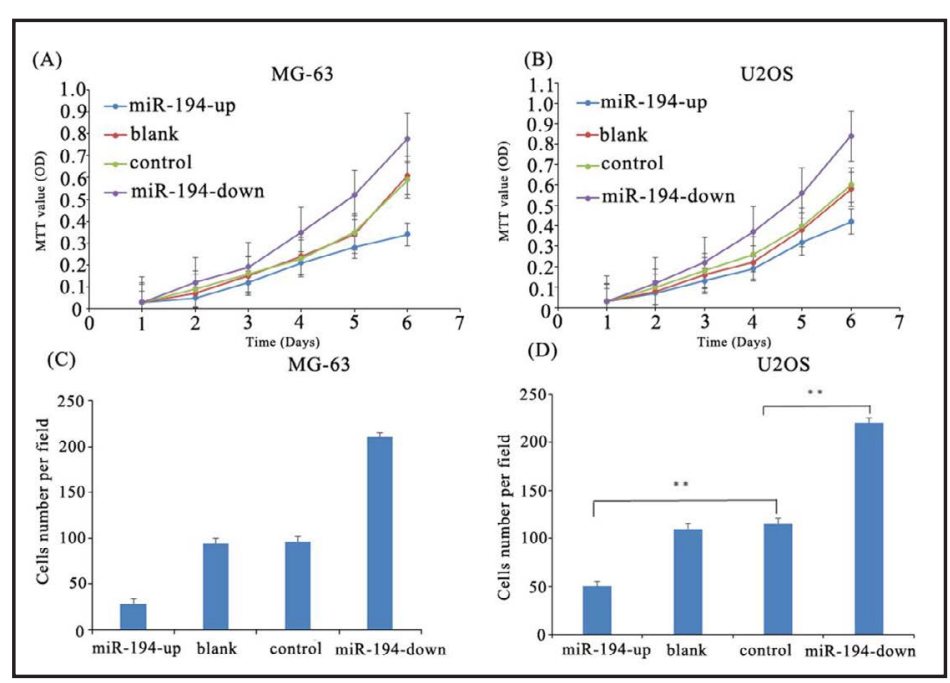

Fig. 2. miR-194 inhibited cell proliferation and migration in both MG63 and U20S cell lines. MTT assay of four groups of MG-63 (A) and U20S (B) cells. The viable cell number was evaluated as the absorbance at $490 \mathrm{~nm}$ with a reference wavelength of $630 \mathrm{~nm}$. Values of optical density (OD) were expressed as the means \pm SD. Quantitative results of the migration in each group of MG-63 (C) or U20S (D) cells were presented, $16 \mathrm{~h}$ after incubation. to their respective $\mathrm{NCs}$

(Fig. 3A\&B, P<0.01). The apoptosis rates of MG-63 and U2OS cells transfected with miR- 
194 mimics $(3.7 \%$ and $3.9 \%$ ) were much higher than those transfected with blank $(1.5 \%$ and $1.7 \%)$ and control $(1.7 \%$ and $1.4 \%)$ groups (Fig. 3C\&D, $\mathrm{P}<0.01$ ). In addition, the apoptosis rates of miR-194 knocked down in MG-63 and U2OS cells were significantly decreased, compared with the blank and control groups (Fig. $3 \mathrm{C} \& \mathrm{D}, \mathrm{P}<0.01$ ).

\section{CDH2 is a direct target} of miR-194

The potential targets of miR-194 were predicted by bioinformatics (Targetscan) and confirmed by luciferase reporter assay. The predicted miR-194 binding sequence in the $\mathrm{CDH} 2$ 3'UTR is shown in Fig. 4A. The relative luciferase activity of the construct with the wild-type 3'-UTR was significantly repressed following miR-194 mimic transfection and increased following miR-194 inhibitor transfection, compared to their respective NCs (Fig. $4 \mathrm{~B}, \mathrm{P}<0.05$ ).

The qRT-PCR and western blot results showed that $\mathrm{CDH} 2$ mRNA and protein were significantly more highly expressed in U20S and MG-63 cells than in hFOB cells (Fig. 5A, $\mathrm{P}<0.05$ ). Transfection of miR-194 mimic significantly decreased the expression level of CDH2 mRNA and protein, while transfection of miR-194 inhibitor increased the expression levels, compared to NCs (Fig. 5B, $\mathrm{P}<0.05$ ). These results showed that miR194 downregulated CDH2 expression via directly targeting its 3'UTR region.

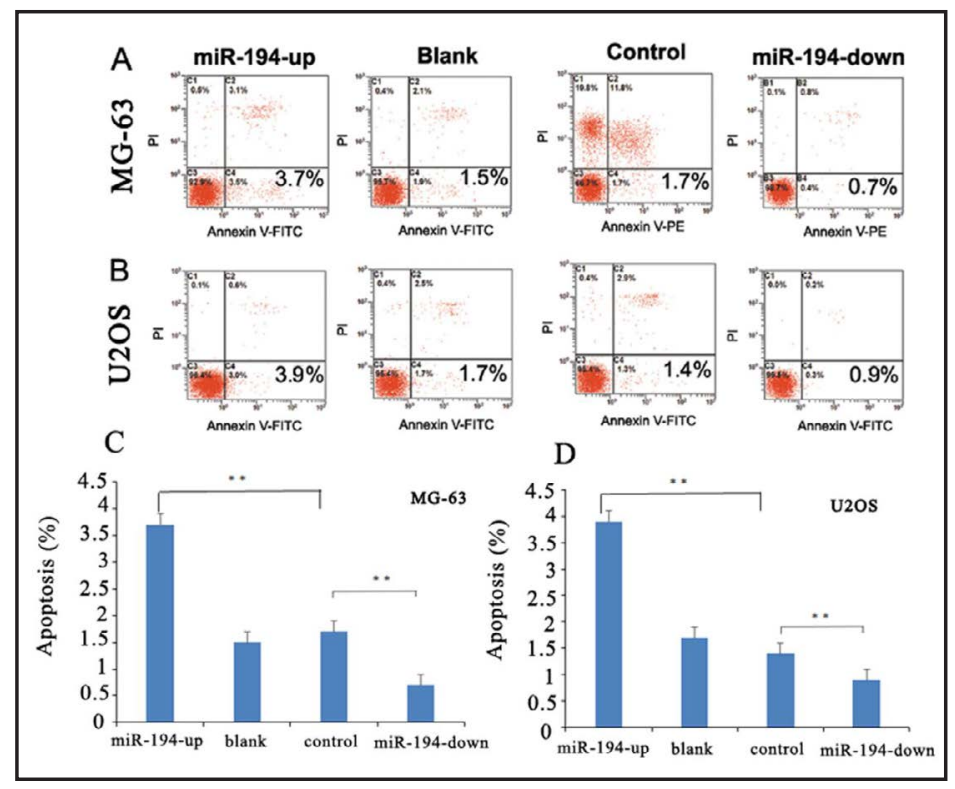

Fig. 3.miR-194 induced apoptosis in both MG-63 and U20S cells. (A and C) Apoptosis of MG-63 cells was measured using FACS with Annexin V and propidium iodide (PI) staining. (B and D) Apoptosis of U20S was measured by FACS with Annexin $\mathrm{V}$ and propidium iodide staining. The data were presented as the means \pm SD in $\mathrm{C}$ and $\mathrm{D},{ }^{* *} \mathrm{P}<0.01$.

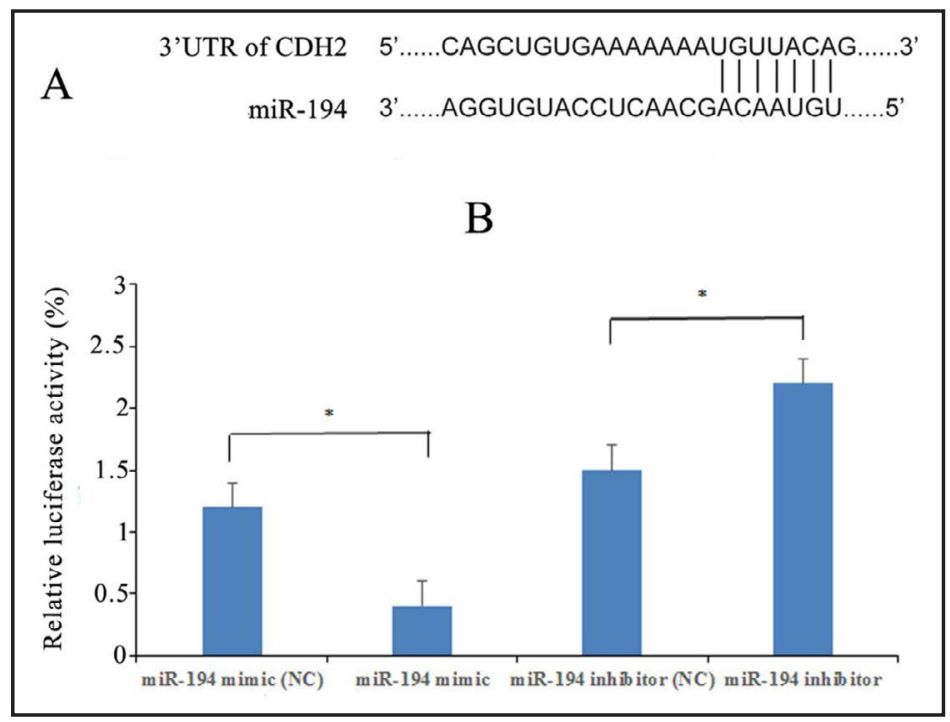

Fig. 4. $\mathrm{CDH} 2$ was a downstream target of miR-194. (A) The predicted miR-194 binding sequence in the CDH2 3'UTR. (B) Analysis of luciferase activity after transfection with the luciferase reporter plasmid wild type CDH2 3'UTR in the presence of miR-194 mimic, miR-194 inhibitor, or their respective negative controls (NC) in U20S cells. Data are represented by the means \pm SD from three independent experiments $(* \mathrm{P}<0.05)$. 
Fig. 5. miR-194 downregulated the expression level of $\mathrm{CDH} 2$. (A) The expression levels of $\mathrm{CDH} 2$ mRNA and protein in hFOB, U2OS and MG-63 cells were measured by qRT-PCR and western blot, respectively; (B) Transfection of miR-194 mimic, miR-194 inhibitor, to decrease and increase the CDH2 mRNA and protein expression in U20S, respectively. Data are represented by the means \pm SD from three independent experiments $\left({ }^{*} \mathrm{P}<0.05\right)$.

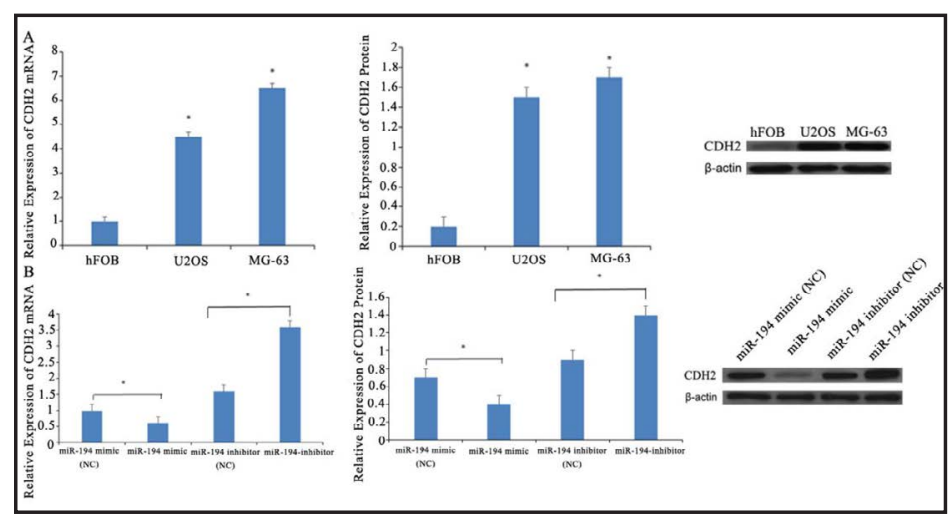

Fig. 6. $\mathrm{miR}-194$ was inversely correlated with CDH2. (A) The expression level of miR-194 was downregulated in osteosarcoma cancer samples

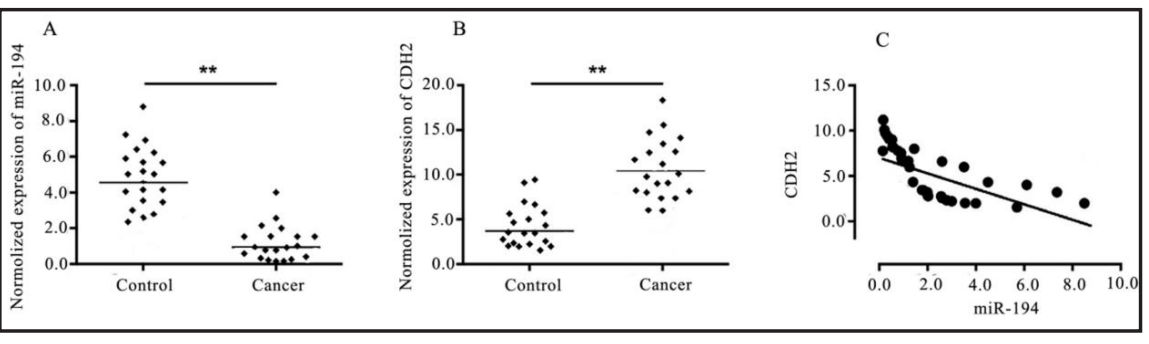
$(n=20)$, as determined by qRT-PCR; (B) the expression level of CDH2 was up-regulated in osteosarcoma cancer samples $(\mathrm{n}=20)$, as determined by qRT-PCR; (C) Spearman's correlation analysis between miR-194 and CDH2 mRNA levels $\left({ }^{*} \mathrm{P}<0.05 ; * * \mathrm{P}<0.01\right)$.

miR-194 is inversely correlated with CDH2 in osteosarcoma cancer tissues

The qRT-PCR results showed that the expression of miR-194 was significantly lower in osteosarcoma cancer tissues than that in normal adjacent tissues (Fig. 6A, $\mathrm{P}<0.05$ ), while the expression level of $\mathrm{CDH} 2$ was significantly higher in osteosarcoma cancer tissues, compared to that in normal adjacent tissues (Fig. 6B, P<0.05). Spearman's correlation analysis showed that the expression level of miR-194 and CDH2 mRNA were inversely correlated (Fig. 6C, $\mathrm{P}<0.05$ ).

\section{Discussion}

Osteosarcoma is the most common human primary malignant bone tumour and is mainly characterized by localized pain and early metastasis. Although it can be treated by surgery and chemotherapy, the clinical prognosis remains poor. In recent years, many studies have indicated that miRNAs play a role in the development of osteosarcoma, with several miRNAs found to be aberrantly expressed in osteosarcoma development [11-13]. Our study demonstrated that miR-194 may play an antioncogenic role in the development of osteosarcoma.

miR-194 plays an important role in many pathological and physiological processes [1416]. miR-194 has been suggested as a tumour suppressor that inhibits cell proliferation through targeting various target genes in numerous cancers [17, 18-20]. The expression of miR-194 was decreased in gastric cancer [21], laryngeal squamous cell carcinoma [22] and neuroblastoma [23], and the overexpression of miR-194 could inhibit tumour growth and enhance the sensitivity of tumours to radiotherapy and chemotherapy. In the past decades, an increasing number of studies concerning the relationship between miR-194 and osteosarcoma have been published. Several studies have reported that miR-194 determined osteosarcoma poor outcome and suppressed tumour growth [24-26]. 


\section{Cellular Physiology Cell Physiol Biochem 2018;45:1966-1974

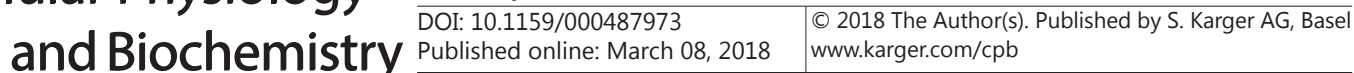 \\ Miao et al.: MiR-194 Down-Regulation of Osteosarcoma by Targeting CDH2}

In the current study, we first validated that the expression levels of miR-194 were decreased in both osteosarcoma tissues and osteosarcoma cells. To explore the potential role of miR-194 in osteosarcoma, miR-194 lentivirus was used to transfect osteosarcoma cells. MTT assay results indicated that miR-194 significantly inhibited cell proliferation in osteosarcoma cells. Flow cytometry assay results showed that miR-194 promotes osteosarcoma cell apoptosis, and a transwell assay revealed that miR-194 inhibited osteosarcoma cell motility.

In the present study, we demonstrated that the expression level of miR-194 was significantly downregulated in osteosarcoma cancer cell lines and clinical tissues. Overexpression of miR-194 inhibited cell proliferation and migration in U2OS and MG-63 cells. This may at least provide some insights into the tumour-suppressive mechanism of miR-194 in osteosarcoma cancer.

Previous studies have also highlighted the important role miR-194 has in regulating cellular differentiation. miR-194, for example, was able to regulate the differentiation of intestinal epithelial cells by targeting the hepatocyte nuclear factor-1 $\alpha$ [27]. It was also reported that miR-194 modulated chondrogenic differentiation of adipose-derived stem cells by targeting SOX5 mRNA [28]. Interestingly, miR-194 inhibited the proliferation and promoted the differentiation of keratinocytes by targeting GRHL2 [29].

$\mathrm{CDH} 2$ (N-cadherin) is acknowledged as a marker of an invasive, malignant state of tumours. In some epithelial cancer types, cells acquire motility and invasiveness by upregulating $\mathrm{N}$-cadherin to the determent of E-cadherin [30]. This switch of cadherin subtype expression is observed in breast [31], prostate [32] and lung cancer cells [33]. Transfection of exogenous CDH2 into breast cancer cells increases cell migration, invasion and metastasis. Blocking of stromal $\mathrm{N}$-cadherin function reverses this attachment, suggesting that $\mathrm{CDH} 2$ is involved in cancer cell engraftment to stroma in invasive tumours [34]. Therefore, we hypothesized that CDH2 might be a direct target gene of miR-194 in osteosarcoma cells, and our results confirmed this hypothesis.

Using bioinformatics, we identified $\mathrm{CDH} 2$ as a potential target of miR-194. A luciferase reporter assay showed that miR-194 downregulated the expression levels of CDH2 mRNA and protein. More importantly, our clinical samples further showed that the expression level of miR-194 was inversely correlated with that of the CDH2 mRNA expression level, which may suggest that $\mathrm{CDH} 2$ acts as an oncogene to promote cell proliferation and migration in osteosarcoma cancer.

Altogether, to the best of our knowledge, this study is the first to report that miR-194 promotes proliferation and migration and suppresses apoptosis of osteosarcoma cells by directly targeting CDH2. Our results suggested that overexpression of $\mathrm{CDH} 2$ was involved in osteosarcoma carcinogenesis. The inhibitory effect of miR-194 on the proliferation and migration of osteosarcoma cells was reversed by overexpressing $\mathrm{CDH} 2$, implicating that miR-194 inhibited osteosarcoma tumourigenesis by suppressing the expression of CDH2.

\section{Conclusion}

Our investigation showed that miR-194 was downregulated in human osteosarcoma tissues and cell lines. miR-194 could inhibit proliferation and migration of osteosarcoma cells and promote apoptosis of osteosarcoma cells through downregulating the expression of CDH2, suggesting miR-194/CDH2 as a novel therapeutic target for osteosarcoma treatment. This study may provide new insight into the mechanisms of osteosarcoma carcinogenesis.

\section{Acknowledgements}

The New Xiangya Talent Projects of the Third xiangya hospital of Central South University (Number: JY201502), This research is supported by a grant from the National Natural 


\section{Cellular Physiology Cell Physiol Biochem 2018;45:1966-1974

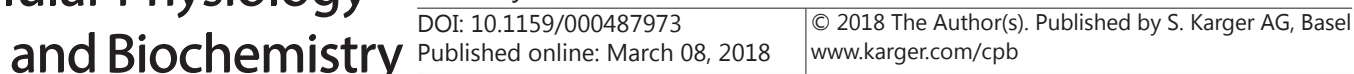

Miao et al.: MiR-194 Down-Regulation of Osteosarcoma by Targeting CDH2

Science Foundation of China (NO. 81772866) and National Natural Science Foundation of China (N0.81502331), supported by the construct program of the key discipline in hunan province.

\section{Disclosure Statement}

No conflict of interests exists.

\section{References}

Ottaviani G, Jaffe N: The epidemiology of osteosarcoma. Cancer Treat Res 2009;152:3-13.

Wu PK, Chen WM, Chen CF, Lee OK, Haung CK, Chen TH: Primary osteogenic sarcoma with pulmonary metastasis: clinical results and prognostic factors in 91 patients. Jpn J Clin Oncol 2009;39:514-522. Zamore PD, Haley B: Ribo-gnome:the big world of small RNAs. Science 2005;309:1519-1524.

Witjes JA, Compérat E, Cowan NC, De Santis M, Gakis G, Lebret T, Ribal MJ, Van der Heijden AG, Sherif A, European Association of Urology: EAU guidelines on muscle-invasive and metastatic bladder cancer: summary of the 2013 guidelines. Eur Urol 2014;65:778-792.

-5 Cooke G, Armstrong ME, Donnelly SC: Donnelly, Macrophage migration inhibitory factor (MIF), enzymatic activity and the inflammatory response. Biofactors 2009; 35:165-168.

6 Bucala R, Donnelly SC: Macrophage migration inhibitory factor: a probable link between inflammation and cancer. Immunity 2007;26:281-285.

7 Oliveira CS, De Bock CE, Molloy TJ, Sadeqzadeh E, Geng XY, Hersey P, Zhang X-D, Thorne RF: Macrophage migration inhibitory factor engages PI3K/Akt signaling and is a prognostic factor in metastatic melanoma. BMC Cancer 2014;14:630.

8 Bao C, Li Y, Huan L, Zhang Y, Zhao F, Wang Q Liang L, Ding J, Liu L, Chen T, Li J, Yao M, Huang S, He X: NFkappaB signaling relieves negative regulation by miR-194 in hepatocellular carcinoma by suppressing the transcription factor HNF-1alpha. Sci Signal 2015;8:ra75.

9 Chen X, Wang Y, Zang W, Du Y, Li M, Zhao G: miR-194 targets RBX1 gene to modulate proliferation and migration of gastric cancer cells. Tumour Biol 2015; 36:2393-2401.

-10 Chi H: miR-194 regulated AGK and inhibited cell proliferation of oral squamous cell carcinoma by reducing PI3K-Akt-Fox03a signaling. Biomed Pharmacother 2015;71:53-57.

11 Zhou X, Ji G, Chen H, Jin W, Yin C, Zhang G: Clinical role of circulating miR-223 as a novel biomarker in early diagnosis of cancer patients. Int J Clin Exp Med 2015;9:16890-16898.

-12 Eto K, Iwatsuki M, Watanabe M, Ishimoto T, Ida S, Imamura Y, Iwagami S, Baba Y, Sakamoto Y, Miyamoto Y, Yoshida N, Baba H: The sensitivity of gastri ccancer to trastuzumab is regulated by the miR-223/FBXW7 pathway. Int J Cancer 2015;136:1537-1545.

13 Jung KH, McCarthy RL, Zhou C, Uprety N, Barton MC, Beretta L: MicroRNA regulates hepatocytic differentiation of progenitor cells by targeting YAP1. Stem Cells 2016;34:1284-1296.

-14 Li J, He X, Wei W, Zhou X: MicroRNA-194 promotes osteoblast differentiation via downregulating STAT1. Biochem Biophys Res Commun 2015;460:482-488.

15 Xu J, Kang Y, Liao WM, Yu L: MiR-194 regulates chondrogenic differentiation of human adipose-derived stem cells by targeting Sox5. PLoS One 2012;7:e31861.

-16 Hino K, Tsuchiya K, Fukao T, Kiga K, Okamoto R, Kanai T, Watanabe M: Inducible expression of microRNA-194 is regulated by HNF-1alpha during intestinal epithelial cell differentiation. RNA 2008;14:1433-1442.

17 Liang T, Li L, Cheng Y, Ren C, Zhang G: MicroRNA-194 promotes the growth, migration, and invasion of ovarian carcinoma cells by targeting protein tyrosine phosphatase non receptor type 12. Onco Targets Ther 2016;9:4307-4315.

18 Tian H, Liu C, Zou X, Wu W, Zhang C, Yuan D: MiRNA-194 regulates palmitic acid-induced toll-like receptor 4 inflammatory responses inTHP-1Cells. Nutrients 2015;7:3483-3496.

19 Zhang M, Zhuang Q, Cui L: MiR-194 inhibits cell proliferation and invasion via repression of RAP2B in bladder cancer. Biomed Pharmacother 2016;80:268-275. 


\section{Cellular Physiology Cell Physiol Biochem 2018;45:1966-1974 \begin{tabular}{c|l|l} 
DOI: 10.1159/000487973 & Ond Biochemistry Published online: March 08, 2018 & $\begin{array}{l}\text { 2018 Tuthor(s). Published by S. Karger AG, Basel } \\
\text { www.karger.com/cpb }\end{array}$
\end{tabular}

20 Zhao Y, Li F, Zhang X, Liu A, Qi J, Cui H, Zhao P: MicroRNA-194 acts as a prognostic marker and inhibits proliferation in hepatocellular carcinoma by targeting MAP4K4 Int J Clin Exp Pathol 2015;8:12446-12454.

21 Shiotani A, Uedo N, Iishi H, Murao T, Kanzaki T, Kimura Y, Kamada T, Kusunoki H, Inoue K, Haruma K: H. pylori eradication did not improvedysregulation of specific oncogenic miRNAs in intestinal metaplastic glands. J Gastroenterol 2012;47:988-998.

22 Zhao M, Wang LT, Liang GP, Zhang P, Deng XJ, Tang Q, Zhai HY, Chang CC, Su YW, Lu QJ: Up-regulation of microRNA-210 induces immune dysfunction via targeting FOXP3 in CD4(+) T cells of psoriasis vulgaris. Clin Immunol 2014;150:22-30.

-23 Tian H, Liu C, Zou X, Wu W, Zhang C, Yuan D: MiRNA-194 regulates palmitic acid-induced toll-like receptor 4 inflammatory responses inTHP-1Cells. Nutrients 2015;7:3483-3496.

-24 Zhang M, Zhuang Q, Cui L: MiR-194 inhibits cell proliferation and invasion via repression of RAP2B in bladder cancer. Biomed Pharmacother 2016;80:268-275.

25 Zhao Y, Li F, Zhang X, Liu A, Qi J, Cui H, Zhao P: MicroRNA-194 acts as a prognostic marker and inhibits proliferation in hepatocellular carcinoma by targeting MAP4K4 Int J Clin Exp Pathol 2015;8:12446-12454.

-26 Chi H: miR-194 regulated AGK and inhibited cell proliferation of oral squamous cell carcinoma by reducing PI3K-Akt-FoxO3a signaling. Biomed Pharmacother 2015;71:53-57.

27 Hino K, Tsuchiya K, Fukao T, Kiga K, Okamoto R, Kanai T, Watanabe M: Inducible expression of microRNA-194 is regulated by HNF-1 alpha during intestinal epithelial cell differentiation. RNA 2008;14:1433-1442.

28 Xu J, Kang Y, Liao WM, Yu L: MiR-194 regulates chondrogenic differentiation of human adipose-derived stem cells by targeting Sox5. PLoS One 2012;7:e31861.

-29 Pivarcsi A, Bodai L, Réthi B, Kenderessy-Szabó A, Koreck A, Széll M, Beer Z, Bata-Csörgoo Z, Magócsi M, Rajnavölgyi E, Dobozy A, Kemény L: Expression and function of Toll-like receptors 2 and 4 in human keratinocytes. Int Immunol 2003;15:721-730.

-30 Li G, Satyamoorthy K, Herlyn M: N-cadherin-mediated intercellular interactions promote survival and migration of melanoma cells. Cancer Res 2001;61:3819-3825.

-31 Rieger-Christ KM, Lee P, Zagha R, Kosakowski M, Moinzadeh A, Stoffel J, Ben-Ze'ev A, Libertino JA, Summerhayes IC: Novel expression of N-cadherin elicits in vitro bladder cell invasion via the Akt signaling pathway. Oncogene 2004;23:4745-4753.

-32 Kolijn K, Verhoef EI, van Leenders GJ: Morphological and immunohistochemical identification of epithelialto-mesenchymal transition in clinical prostate cancer. Oncotarget 2015;6:24488-24498.

-33 Taeger J, Moser C, Hellerbrand C, Mycielska ME, Glockzin G, Schlitt HJ, Geissler EK, Stoeltzing O, Lang SA: Targeting FGFR/PDGFR/VEGFRimpairs tumor growth, angiogenesis, and metastasis by effects on tumor cells,endothelial cells, and pericytes in pancreatic cancer. Mol Cancer Ther 2011;10:2157-2167.

34 McAndrews KM, Yi J, McGrail D-J, Dawson MR: Enhanced adhesion of stromal cells to invasive cancer cells regulated by cadherin 11. ACS Chem Biol 2015;10:1932-1938. 